\title{
ANALISIS QUALITY OF SERVICE JARINGAN LOAD BALANCING MENGGUNAKAN METODE PCC DAN NTH
}

\author{
Zawiyah Saharuna ${ }^{1}$, Rini Nur ${ }^{2}$, Ahmad Sandi $^{3}$
}

\author{
${ }^{123}$ Politeknik Negeri Ujung Pandang \\ Jl. Perintis Kemerdekaan KM 10 Tamalanrea Makassar \\ Izawiyah@poliupg.ac.id, ${ }^{2}$ rini@poliupg.ac.id
}

\begin{abstract}
Abstrak - Penelitian ini menganalisis kinerja dari dua metode load balancing yaitu Nth dan Per Connection Classifier (PCC). Kedua metode tersebut diimplementasikan pada suatu topologi jaringan yang menggunakan dua line ISP dengan memberikan parameter limit bandwidth setiap ISP. Implementasi metode load balancing dilakukan menggunakan MikroTik RouterBoard. Pengujian yang dilakukan adalah dengan mengukur kinerja konektifitas jaringan, mekanisme failover dan Quality of Service (QoS) jaringan dari kedua metode load balancing. Hasil penelitian menunjukkan bahwa penerapan load balancing dapat menyeimbangkan nilai throughput dan meminimalkan nilai packet loss. Nilai throughput pada Nth lebih stabil disetiap client daripada PCC. Namun nilai packet loss pada PCC lebih kecil daripada Nth. Nilai delay dan jitter tidak berpengaruh pada penerapan load balancing, namun PCC memiliki nilai delay dan nilai jitter yang lebih kecil dibandingkan Nth. Mekanisme failover berjalan baik pada kedua metode load balancing, namun mekanisme failover pada Nth lebih cepat daripada PCC dengan nilai downtime sebesar 3 detik.
\end{abstract}

Kata Kunci-Load Balancing, PCC, Nth, QoS.

Abstract-This study analyses the performance of two load balancing methods, namely Nth and Per Connection Classifier (PCC). Both methods are implemented in a network topology that uses two ISP lines by providing bandwidth limit parameters for each ISP. The load balancing method is implemented using MikroTik RouterBoard. Tests carried out are to measure the performance of network connectivity, failover mechanisms and Quality of Service (QoS) of both loadbalancing methods. The results showed that the implementation of load balancing could balance the value of throughput and minimize the value of packet loss. The throughput value on Nth is more stable in each client than PCC. But the packet loss value at PCC is smaller than Nth. Delay and jitter values have no effect on the application of load balancing, but PCC has smaller delay and jitter values than Nth. The failover mechanism works well on both load balancing methods, but the failover mechanism on Nth is faster than PCC with a downtime value of 3 seconds.

Keywords—Load Balancing, PCC, Nth, QoS.

\section{PENDAHULUAN}

Pada jaringan, ketika datang banyak beban trafik dan request dari pengguna jaringan, maka bisa jadi salah satu jalur koneksi (gateway) pada sistem jaringan akan menjadi lebih terbebani sehingga terjadi kemacetan. Solusi yang dapat dilakukan adalah dengan cara membagi-bagi beban trafik tersebut sehingga tidak berpusat pada salah satu jalur koneksi saja [1]. Teknik inilah yang disebut dengan teknik load balancing. Load balancing adalah teknik untuk mendistribusikan beban trafik pada dua atau lebih jalur koneksi secara seimbang, agar trafik dapat berjalan optimal, memaksimalkan throughput, memperkecil waktu tanggap dan menghindari overload pada salah satu jalur koneksi [2].

Pada Mikrotik, implementasi load balancing dapat dilakukan dengan berbagai metode seperti Equal Cost Multi Path (ECMP), Nth, dan Per Connection
Classifier (PCC) [3]. Kajian mengenai ketiga metode load balancing tersebut telah dilakukan. Seperti implementasi ECMP pada jaringan DISKOMINFO Tenggarong menggunakan parameter jitter, delay, throughput, Round Trip Time (RTT), dan failover [4]. Untuk implementasi Nth pada jaringan juga banyak dilakukan, diantaranya adalah implementasi pada dua ISP yang mempertimbangkan parameter bandwidth [5], implementasi dengan dua jalur koneksi dengan mengatur parameter Nth 2,1 dan Nth 2,2 pada mangle MikroTik [6], implementasi dua ISP dengan mempertimbangkan bandwidth dan mekanisme failover [7], dan implementasi Nth pada multiple gateway (tiga ISP) dengan mempertimbangkan parameter throughput, delay, dan packet loss [8]. Selanjutnya adalah implementasi PCC pada topologi load balancing dan proxy server jaringan Shmily.net dengan mempertimbangkan jumlah pengguna yang mengakses [9]. PCC juga diimplementasikan pada 
jaringan internet PT PLN WS2JB area Palembang dengan mengukur parameter delay, packet loss, jitter, availability, dan throughput [10].

Selain itu, beberapa peneliti juga melakukan studi komparasi ketiga metode load balancing tersebut. Seperti perbandingan antara metode Nth dan PCC pada dua jalur koneksi dengan mempertimbangkan nilai throughput, packet loss dan fairness index [11]. Perbandingan antara ECMP, Nth, dan PCC saat diimplementasikan dengan mempertimbangkan parameter penggunaan Network Address Translation (NAT), dan mekanisme failover [3].

Pada penelitian ini membandingkan antara metode load balancing Nth dan PCC menggunakan perangkat MikroTik router board pada jaringan gateway dua ISP dengan mempertimbangkan parameter throughput, packet loss, delay, jitter, dan downtime.

\section{QUALITY OF SERVICE}

Quality of Service (QoS) adalah kemampuan suatu jaringan untuk menyediakan layanan yang lebih baik pada traffic data tertentu pada berbagai jenis platform teknologi. QoS tidak diperoleh langsung dari infrastruktur yang ada, melainkan diperoleh dengan mengimplementasikannya pada jaringan yang bersangkutan [12]. QoS dirancang untuk membantu pengguna menjadi lebih produktif dengan memastikan bahwa pengguna mendapatkan kinerja yang handal dari aplikasi berbasis jaringan. Parameter-parameter QoS adalah throughput, packet loss, delay, jitter, dan downtime.

Throughput merupakan besarnya data yang mampu dikirimkan oleh jaringan dari sumber ke tujuan dalam satu satuan waktu. Throughput terkadang disebut dengan bandwidth karena throughput merupakan nilai suatu bandwidth dalam kondisi ril. Bandwidth lebih bersifat tetap, sedangkan throughput sifatnya dinamis tergantung traffic yang sedang terjadi [13].

Berdasarkan standar dari ETSI-TIPHON, throughput dapat dikategorikan seperti pada Tabel 1.

TABEL I

KATEGORI THROUGHPUT

\begin{tabular}{|l|c|c|}
\hline $\begin{array}{c}\text { Kategori } \\
\text { Throughput }\end{array}$ & Throughput & Index \\
\hline Sangat Bagus & $76 \%-100 \%$ & 4 \\
\hline Bagus & $51 \%-75 \%$ & 3 \\
\hline Sedang & $26 \%-50 \%$ & 2 \\
\hline Buruk & $<25 \%$ & 1 \\
\hline
\end{tabular}

(Sumber: ETSI-TIPHON)

TABEL II

KATEGORI PACKET LOSS

\begin{tabular}{|l|c|c|}
\hline $\begin{array}{c}\text { Kategori } \\
\text { Packet Loss }\end{array}$ & Packet Loss & Index \\
\hline Sangat Bagus & $0 \%-2 \%$ & 4 \\
\hline Bagus & $3 \%-14 \%$ & 3 \\
\hline Sedang & $15 \%-24 \%$ & 2 \\
\hline Buruk & $>25 \%$ & 1 \\
\hline
\end{tabular}

(Sumber: ETSI-TIPHON)
Packet loss merupakan selisih antara jumlah packet yang dikirim dengan jumlah paket yang diterima atau dengan kata lain packet loss adalah besarnya paket yang mengalami kegagalan transmisi sehingga tidak sampai di tujuan [14].

Berdasarkan standar dari ETSI-TIPHON, packet loss dapat dikategorikan seperti pada Tabel 2.

Delay merupakan waktu tunda seluruh paket yang berhasil dikirim dari sumber ke tujuan [15]. Waktu tunda mempengaruhi kualitas layanan (QoS) karena waktu tunda menyebabkan suatu paket lebih lama mencapai tujuan.

Berdasarkan standard dari ETSI-TIPHON, delay dapat dikategorikan seperti pada Tabel 3.

TABEL III KATEGORI DELAY

\begin{tabular}{|l|c|c|}
\hline $\begin{array}{c}\text { Kategori } \\
\text { Delay }\end{array}$ & Delay & Index \\
\hline Sangat Bagus & $<150 \mathrm{~ms}$ & 4 \\
\hline Bagus & $150-300 \mathrm{~ms}$ & 3 \\
\hline Sedang & $300-450 \mathrm{~ms}$ & 2 \\
\hline Buruk & $>450 \mathrm{~ms}$ & 1 \\
\hline
\end{tabular}

(Sumber: ETSI-TIPHON)

Jitter adalah variasi delay antar paket yang terjadi dalam jaringan. Besarnya nilai jitter dipengaruhi oleh variasi beban trafik dan besarnya congesti dalam jaringan. Padatnya trafik dalam jaringan dapat menyebabkan terjadinya congesti sehingga nilai jitter anak semakin meningkat. Peningkatan nilai jitter akan menurunkan performa jaringan [13].

TABEL IV

KATEGORI JITTER

\begin{tabular}{|l|c|c|}
\hline \multicolumn{1}{|c|}{$\begin{array}{c}\text { Kategori } \\
\text { Jitter }\end{array}$} & Peak Jitter & Index \\
\hline Sangat Bagus & $0 \mathrm{~ms}$ & 4 \\
\hline Bagus & $1-75 \mathrm{~ms}$ & 3 \\
\hline Sedang & $76-450 \mathrm{~ms}$ & 2 \\
\hline Buruk & $>450 \mathrm{~ms}$ & 1 \\
\hline
\end{tabular}

(Sumber: ETSI-TIPHON)

Downtime adalah waktu (period of time) sistem tidak dapat digunakan untuk menjalankan fungsinya sesuai yang diharapkan. Downtime sangat berpengaruh pada nilai availability dari suatu perangkat [12]. Jumlah downtime yang lama pada jaringan sangat mempengaruhi kinerja maupun kerugian dari sisi cost.

\section{METODE PENELITIAN}

Tahapan penelitian mengikuti diagram fishbone seperti yang ditunjukkan pada Gambar 1. Diagram tersebut merangkum rangkaian pelaksanaan penelitian secara keseluruhan.

Desain topologi jaringan yang digunakan adalah topologi jaringan sebelum dan setelah penerapan load balancing seperti yang ditampilkan pada Gambar 2 dan Gambar 3. 


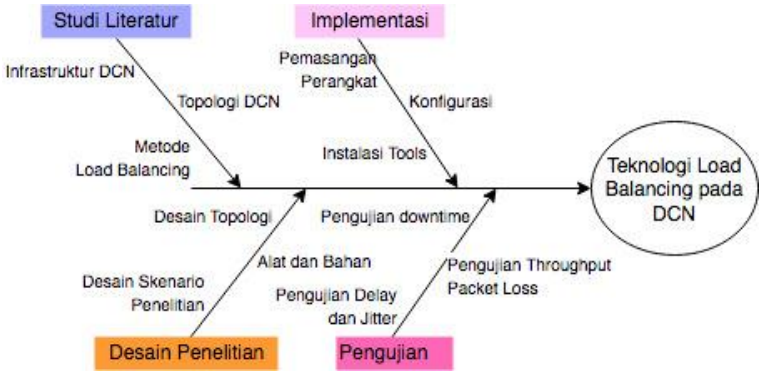

Gbr. 1 Diagram fishbone alur penelitian

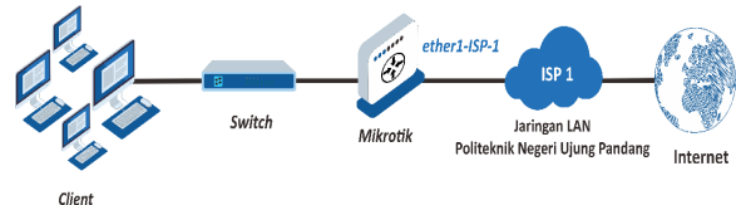

Gbr. 2 Topologi jaringan sebelum penerapan load balancing

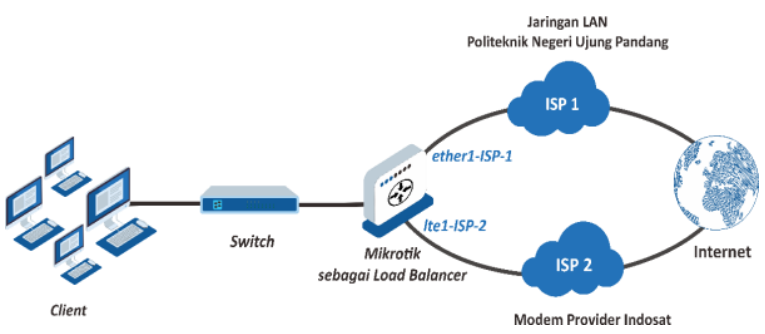

Gbr. 3 Topologi jaringan setelah penerapan load balancing

Kondisi jaringan sebelum penerapan load balancing hanya menggunakan satu link ISP yaitu dari koneksi LAN kampus PNUP, sedangkan kondisi jaringan setelah penerapan load balancing menggunakan dua link ISP dengan menambahkan satu link ISP menggunakan perangkat modem.

Pengujian setelah penerapan load balancing menggunakan limit bandwidth dengan perbandingan 1:1 (satu banding satu) Mbps, sehingga untuk pengujian sebelum penerapan load balancing yang hanya menggunakan satu link ISP harus menggunakan total perbandingan limit bandwidth yaitu 2 (dua) Mbps Hal ini dilakukan agar parameter limit bandwidth sebelum dan setelah penerapan load balancing yang diuji memiliki nilai yang sama.

Pengujian dilakukan terhadap semua kondisi jaringan di semua metode load balancing dengan konfigurasi limit bandwidth yang telah ditentukan. Untuk total bandwidth $2 \mathrm{Mbps}$, yang diuji yaitu sebelum penerapan load balancing atau diistilahkan Seb-LB B_2 dan setelah penerapan load balancing yaitu Nth load balance atau diistilahkan Nth B_1:1 dan PCC load balance atau diistilahkan PCC B_1:1.

Pengujian dilakukan sebanyak 10 kali pengujian dengan menggunakan 4 Client. Pengujian QoS teknik load balancing dilakukan dengan tiga kondisi yaitu pengujian saat download file, pengujian saat video conference, dan pengujian ketika terjadi pemutusan link ke salah satu ISP.

\section{IV.HASIL DAN PEMBAHASAN}

\section{A. Hasil Pengujian Saat Download File}

Pengujian download file yang telah dilakukan untuk mengukur kinerja QoS dalam jaringan menggunakan parameter throughput dan packet loss. Hasil pengujian download file adalah sebagai berikut:

\section{1) Throughput}

Pengujian throughput bertujuan untuk mengetahui kemampuan sebenarnya suatu jaringan dalam melakukan pengiriman data per satuan waktu saat sebelum dan setelah penerapan teknik load balancing.

Berdasarkan hasil uji throughput seperti pada Gambar 54 terlihat bahwa Seb-LB B_2 rata-rata nilai throughput dari Client1 hingga Client4 mengalami penurunan. Hal ini terlihat pada rata-rata nilai throughput Client1 sebesar 35,4\%, Client2 sebesar $24,6 \%$, Client 3 sebesar $19,5 \%$ dan Client 4 yang hanya sebesar $17,6 \%$. Salah satu faktor yang mempengaruhi adalah proses download pertama yang dilakukan oleh Client1 mengambil semua kapasitas bandwidth, sehingga ketika Client2 melakukan download, butuh waktu untuk menyesuaikan kapasitas bandwitdh yang digunakan untuk client tersebut. Hal yang sama terjadi pada Client3 dan Client4.

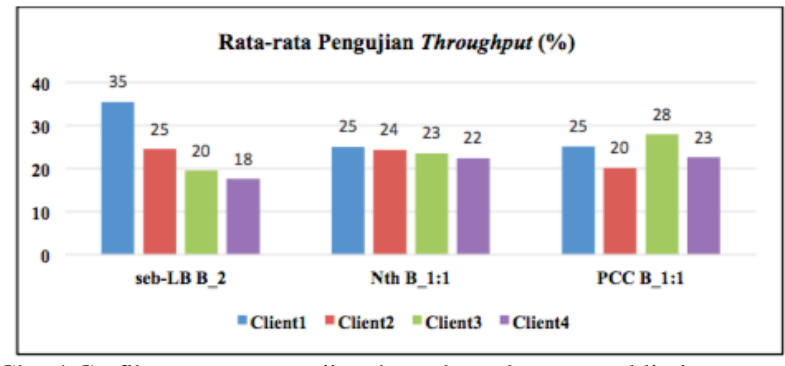

Gbr. 4 Grafik rata-rata pengujian throughput dengan total limit bandwidth $2 \mathrm{Mbps}$

Pada Nth B_1:1 terlihat rata-rata pengujian nilai throughput lebih stabil dibandingakan dengan kedua kondisi pengujian yang lain. Nilai throughput hampir seimbang dengan nilai interval throughput setiap client tidak terlalu besar. Hal ini terlihat pada rata-rata nilai throughput Client1 sebesar 25,0\%, Client2 sebesar 24,3\%, Client3 sebesar 23,5\% dan Client4 yang sebesar $22,3 \%$. Hal ini menandakan bahwa Nth B_1:1 dapat menyeimbangkan pengiriman paket khususnya pada saat proses download file.

Pada PCC B_1:1 terlihat rata-rata pengujian nilai throughput fluktuatif. Hal ini terlihat pada rata-rata nilai throughput Client1 sebesar 25,2\%, Client2 sebesar 20,1\%, Client3 sebesar 28,0\% dan Client4 yang sebesar 22,7\%. Hal ini dikarenakan PCC load balance hanya membagi beban berdasarkan koneksi bukan berdasar jumlah paket.

Berdasarkan dengan data hasil pengujian tersebut, penerapan metode load balancing Nth dan PCC dengan perbandingan limit bandwidth yang sama dapat membagi penggunaan bandwidth disetiap client 
sehingga menghasilkan nilai throughput yang berimbang pada proses download file. QoS throughput dari total semua client pada kedua metode load balancing yang dihasilkan tergolong bagus karena berada diatas angka $75 \%$ berdasarkan standar TIPHON.

\section{2) Packet loss}

Pengukuran packet loss bertujuan untuk mengetahui persentase paket tidak sampai ke tujuan yang terjadi pada jaringan saat sebelum dan setelah penerapan teknik load balancing.

Berdasarkan hasil rata-rata uji packet loss seperti pada Gambar 5 terlihat bahwa Seb-LB B_2 rata-rata nilai packet loss dari Client1 hingga Client4 lebih tinggi dibandingkan Nth_B_1:1 dan PCC B_1:1. Hal ini terlihat pada rata-rata nilai packet loss Client1 sebesar 9,0\%, Client2 sebesar 9,7\%, Client 3 sebesar $9,6 \%$ dan Client4 yang hanya sebesar $9,2 \%$.

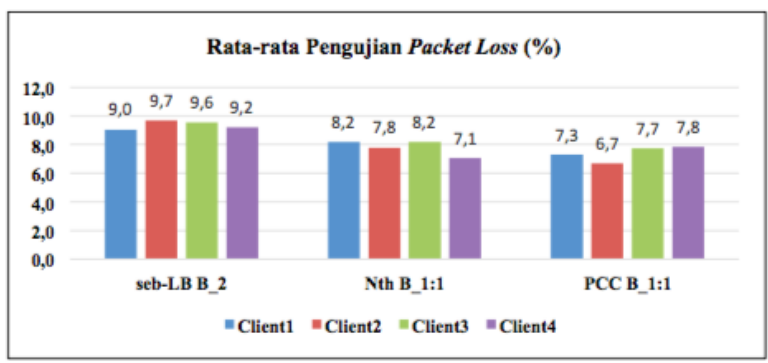

Gbr. 5 Grafik rata-rata pengujian packet loss dengan total limit bandwidth 2 Mbps

Pada Nth B_1:1 terlihat rata-rata pengujian nilai packet loss fluktuatif. Hal ini terlihat pada rata-rata nilai packet loss Client 1 sebesar $8,2 \%$, Client 2 sebesar $7,8 \%$, Client 3 sebesar $8,2 \%$ dan Client4 yang sebesar $7,1 \%$. Hal yang sama didapatkan pada PCC B_1:1, terlihat rata-rata pengujian nilai packet loss fluktuatif. Hal ini terlihat pada rata-rata nilai packet loss Client 1 sebesar 7,3\%, Client2 sebesar 6,7\%, Client3 sebesar $7,7 \%$ dan Client4 yang sebesar 7,8\%. Jika dicermati nilai packet loss PCC B_1:1 lebih kecil dibandingakan dengan nilai packet loss Nth B_1:1. Hal ini dikarenakan Nth load balance mengirimkan paket data melalui beberapa gateway yang berbeda, sehingga dapat terjadi kegagalan pengiriman paket data akibat perubahan gateway. Berbeda dengan PCC load balance yang mengirimkan paket data berdasarkan pasangan alamat sumber dan alamat tujuan sehingga kemungkinan pengiriman paket data lebih kecil.

Berdasarkan dengan data hasil pengujian tersebut, penerapan metode load balancing Nth dan PCC dengan perbandingan limit bandwidth yang sama dapat meminimalkan nilai packet loss pada proses download file. QoS dari packet loss dikedua metode load balancing yang dihasilkan tergolong bagus karena kurang dari $15 \%$ berdasarkan standar TIPHON.

\section{B. Hasil Pengujian Saat Video Conference}

Pengujian saat video conference yang telah dilakukan untuk mengukur kinerja QoS dalam jaringan menggunakan parameter uji delay dan jitter. Hasil pengukuran tersebut adalah sebagai berikut:

\section{1) Delay}

Pengukuran delay bertujuan untuk mengetahui rata-rata jeda waktu antar paket data yang terkirim dari jaringan internet ke client.

Berdasarkan hasil uji delay seperti pada Gambar 6 terlihat bahwa Seb-LB B_2 dari Client1 hingga Client4 mengalami kenaikan rata-rata nilai delay. Hal ini terlihat pada rata-rata nilai delay Client1 sebesar 3,1 ms, Client2 sebesar 3,8 ms, Client3 sebesar 4,3 ms dan Client4 sebesar 4,3 ms. Salah satu faktor yang mempengaruhi adalah proses download pertama yang dilakukan oleh Client1 mengambil semua kapasitas bandwidth, sehingga ketika Client2, Client3 dan Cleint4 secara berurutan melakukan download, butuh waktu untuk menyesuaikan kapasitas bandwitdh yang digunakan untuk setiap client tersebut. Hal tersebut mempengaruhi nilai delay setiap client. Semakin tinggi bandwidth (nilai throughput) yang diperoleh setiap client maka semakin kecil delay yang terjadi.

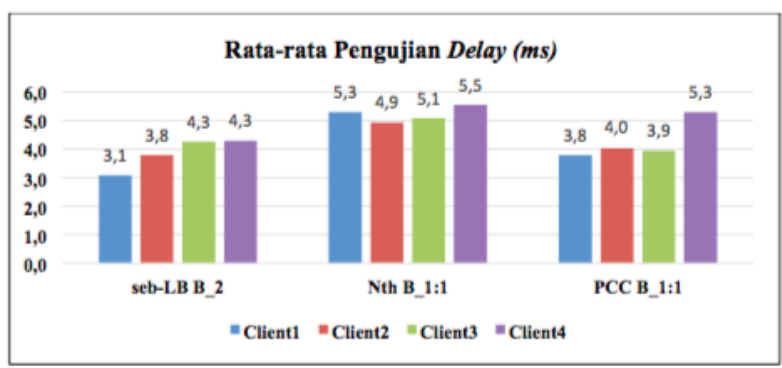

Gbr. 6 Grafik rata-rata pengujian delay dengan total limit bandwidth 2 Mbps

Pada Nth B_1:1 terlihat rata-rata pengujian nilai delay lebih besar dibandingakan dengan kedua kondisi pengujian yang lain. Terlihat pada rata-rata nilai delay Client 1 sebesar 5,3 ms, Client2 sebesar 4,9 ms, Client3 sebesar 5,1 ms dan Client4 yang sebesar 5,5 ms. Hal ini dikarenakan Nth load balance memungkinkan pengiriman data dari beberapa gateway sehingga dari peralihan gateway tersebut bisa menimbulkan delay yang besar pada setiap paket yang dikirim.

Pada PCC B_1:1 terlihat rata-rata pengujian nilai delay fluktuatif. Hal ini terlihat pada rata-rata nilai delay Client 1 sebesar 3,8 ms, Client2 sebesar 4,0 ms, Client3 sebesar 3,9 ms dan Client4 yang sebesar 5,3 ms. Rata-rata nilai delay PCC B_1:1 lebih kecil diripada rata-rata nilai delay $\mathrm{Nth} \mathrm{B}_{-} 1: 1$. Hal ini dikarenakan PCC load balance mengirimkan paket data berdasarkan pasangan alamat sumber dan alamat tujuan sehingga kemungkinan terjadi delay pada pengiriman paket data lebih kecil.

Berdasarkan dengan data hasil pengujian tersebut, delay yang terjadi pada saat sebelum penerapan metode load balancing masih lebih kecil dibandingkan setelah penerapan load balancing khususnya pada 
video conference. Namun delay yang terjadi pada PCC load balance masih lebih kecil dibandingkan dengan Nth load balance dan QoS dari delay dikedua metode load balancing yang dihasilkan tergolong sangat bagus karena kurang dari $150 \mathrm{~ms}$ berdasarkan standar TIPHON.

\section{2) Jitter}

Pengukuran jitter bertujuan untuk mengetahui ratarata variasi delay antar paket data yang terkirim dari jaringan internet ke client.

Berdasarkan hasil uji jitter seperti pada Gambar 7 terlihat bahwa Seb-LB B_2 dari Client1 hingga Client3 mengalami kenaikan rata-rata nilai jitter dan pada Client4 rata-rata nilai jitter turun. Hal ini terlihat pada rata-rata nilai jitter Client1 sebesar $4,3 \mathrm{~ms}$, Client2 sebesar 5,5 ms, Client3 sebesar 6,2 ms dan Client4 sebesar 4,7 ms.

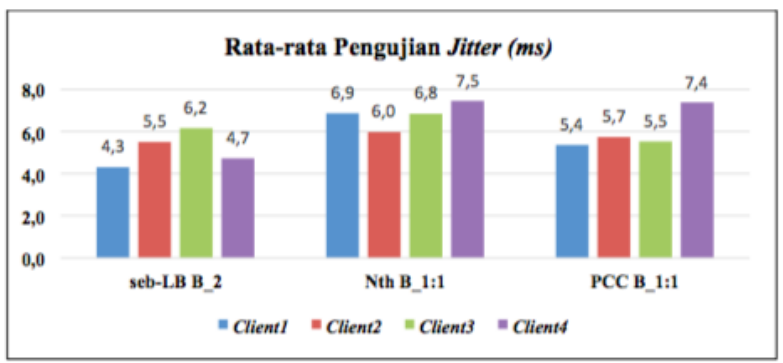

Gbr. 7 Grafik rata-rata pengujian delay dengan total limit bandwidth $2 \mathrm{Mbps}$

Pada Nth B_1:1 terlihat rata-rata pengujian nilai jitter lebih besar dibandingakan dengan kedua kondisi pengujian yang lain. Terlihat pada rata-rata nilai jitter Client 1 sebesar 6,9 ms, Client2 sebesar 6,0 ms, Client3 sebesar 6,8 ms dan Client4 yang sebesar 7,5 ms. Hal ini dikarenakan $\mathrm{Nth}$ load balance memungkinkan pengiriman data dari beberapa gateway sehingga dari peralihan gateway tersebut bisa menimbulkan jitter yang besar setiap paket yang dikirim.

Pada PCC B_1:1 terlihat rata-rata pengujian nilai jitter fluktuatif. Hal ini terlihat pada rata-rata nilai jitter Client 1 sebesar $5,4 \mathrm{~ms}$, Client 2 sebesar $5,7 \mathrm{~ms}$, Client 3 sebesar 5,5 ms dan Client4 yang sebesar 7,4 ms. Rata-rata nilai jitter PCC B_1:1 lebih kecil diripada rata-rata nilai jitter Nth $\mathrm{B}_{-} 1: 1$. Hal ini dikarenakan PCC load balance mengirimkan paket data berdasarkan pasangan alamat sumber dan alamat tujuan sehingga nilai jitter pada pengiriman paket data lebih kecil.

Berdasarkan dengan data hasil pengujian tersebut, maka dapat disimpulkan bahwa jitter yang terjadi pada saat sebelum penerapan metode load balancing masih lebih kecil dibandingkan setelah penerapan load balancing khususnya pada video conference. Namun jitter yang terjadi pada PCC load balance masih lebih kecil dibandingkan dengan Nth load balance dan QoS dari jitter dikedua metode load balancing yang dihasilkan tergolong bagus karena kurang dari $75 \mathrm{~ms}$ berdasarkan standar TIPHON.

\section{Hasil Pengujian Ketika Terjadi Pemutusan Link ke ISP}

Pengujian pemutusan link ISP saat pengiriman paket ping bertujuan untuk mengukur waktu downtime. Paket ping dikirim ke alamat www.google.com menggunakan software Axence NetTools. Pengujian downtime bertujuan untuk mengetahui lama waktu suatu sistem tidak dapat digunakan akibat gangguan yang terjadi pada router. Setelah penerapan teknik load balancing, saat link putus terjadi mekanisme failover dari ISP-1 ke ISP-2 maupun sebaliknya untuk meminimalkan downtime pada jaringan yang ditunjukkan pada Gambar 8.

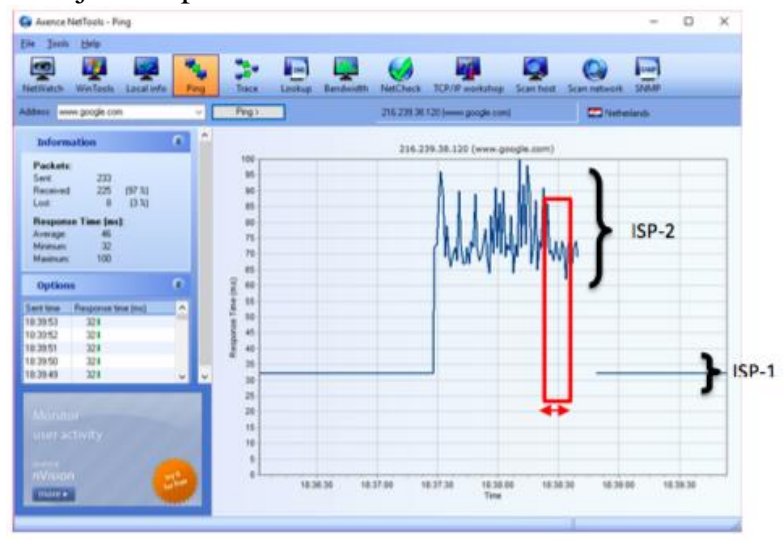

Gbr. 8 Proses failover ketika terjadi pemutusan link

Berdasarkan pengujian yang telah dilakukan, berikut ini data hasil pengujian downtime menggunakan pada kedua metode load balancing yang ditunjukkan pada Tabel 5.

TABEL V

HASIL PENGUJIAN PEMUTUSAN LINK ISP DENGAN TOTAL BANDWIDTH 2 Mbps

\begin{tabular}{|c|c|c|c|c|c|c|c|c|c|c|c|c|c|c|c|c|}
\hline \\
\hline \multirow{2}{*}{ Metode } & \multicolumn{8}{|c|}{ Nth B_1:1 } & \multicolumn{8}{|c|}{ PCC B_1:1 } \\
\hline & \multicolumn{2}{|c|}{ Client1 } & \multicolumn{2}{|c|}{\begin{tabular}{|l|} 
Client2 \\
\end{tabular}} & \multicolumn{2}{|c|}{ Client3 } & \multicolumn{2}{|c|}{\begin{tabular}{|l|} 
Client4 \\
\end{tabular}} & \multicolumn{2}{|c|}{ Client1 } & \multicolumn{2}{|c|}{ Client2 } & \multicolumn{2}{|c|}{\begin{tabular}{|l} 
Client3 \\
\end{tabular}} & \multicolumn{2}{|c|}{ Client4 } \\
\hline $\begin{array}{l}\text { ISP (OFF) } \\
\text { Penguiaan }\end{array}$ & 1 & 2 & 1 & 2 & 1 & 2 & 1 & 2 & 1 & 2 & 1 & 2 & 1 & 2 & 1 & 2 \\
\hline Pengujian 1 & 3,0 & 2,0 & 1,0 & 0,0 & 3,0 & 2,0 & 0,0 & 0,0 & 4,0 & 3,0 & 3,0 & 1,0 & 3,0 & 1,0 & 4,0 & 3,0 \\
\hline Penguj & 0,0 & 1,0 & 1,0 & 0,0 & 3,0 & 2,0 & 1,0 & 0,0 & 0,0 & 3,0 & 3,0 & 1,0 & 0,0 & 3,0 & 0,0 & 4, \\
\hline & 0,0 & 1,0 & 0,0 & 0,0 & 2,0 & 0,0 & 3,0 & 1,0 & 4,0 & 3,0 & 1,0 & 3,0 & 2,0 & 0,0 & 0,0 & $\mathrm{~J}$, \\
\hline Penguji & 3, & 2,0 & 1,0 & 0,0 & 3,0 & 2,0 & 3,0 & 0,0 & 4,0 & 0,0 & 0,0 & 1,0 & 0,0 & 0,0 & 4,0 & 0, \\
\hline Pengu. & 0,0 & 1,0 & 3,0 & 0,0 & 3,0 & 0,0 & 3,0 & 1,0 & 0,0 & 0,0 & , 0 & 0 & 0,0 & 0,0 & 0,0 & 0, \\
\hline & 0,0 & 0,0 & 0,0 & 0,0 & 0,0 & 0,0 & 0,0 & 0,0 & 1,0 & 1,0 & 2,0 & 0,0 & 3,0 & 0,0 & 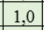 & 1, \\
\hline Peng & 1,0 & 0,0 & 1,0 & 0,0 & 0,0 & 0,0 & 3,0 & 0,0 & 1,0 & 5,0 & 0,0 & 4,0 & 0,0 & 5,0 & 1,0 & 5. \\
\hline 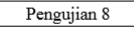 & 0,0 & 0,0 & 0,0 & 0,0 & 0,0 & 0,0 & 0,0 & 0,0 & 1,0 & 1,0 & 3,0 & 0,0 & 4,0 & 2,0 & 1,0 & 2,0 \\
\hline & 0,0 & 0,0 & 0,0 & 0,0 & 0,0 & 0,0 & 0,0 & 0,0 & 3,0 & 0,0 & 0,0 & 1,0 & 1,0 & 0,0 & 0,0 & 1,0 \\
\hline & & & & & & & & & & & & & & & & \\
\hline
\end{tabular}

Berdasarkan Tabel 5, hasil 10 kali pengujian Nth B_1:1 yang dilakukan di setiap client, nilai downtime tertinggi Nth $B_{-} 1: 1$ terdapat pada beberapa pengujian dengan nilai downtime $3,0 \mathrm{~s}$ dan nilai downtime terendah terdapat beberapa pengujian dengan nilai downtime $0 \mathrm{~s}$. Sedangkan hasil 10 kali pengujian PCC B_1:1 yang dilakukan disetiap client, nilai downtime tertinggi PCC B_1:1 terdapat pada beberapa pengujian dengan nilai downtime $5,0 \mathrm{~s}$ dan nilai downtime terendah terdapat pada beberapa pengujian dengan nilai downtime $0 \mathrm{~s}$. 


\section{KESIMPULAN}

Berdasarkan hasil pengujian, maka diperoleh kesimpulan sebagai berikut:

1. Implementasi load balancing menggunakan metode Nth dan PCC yang diterapkan pada Mikrotik RouterBoard berjalan dengan baik dan menghasilkan keseimbangan trafik pada dua line ISP berdasarkan pengaturan limit bandwidth yang digunakan.

2. Berdasarkan 5 parameter QoS yang diuji, hasilnya dijabarkan sebagai berikut:

a. Nilai throughput pada metode Nth lebih stabil pada setiap client dibandingkan dengan metode PCC.

b. Nilai packet loss, delay dan jitter pada metode PCC lebih kecil dibandingkan dengan metode Nth.

c. Nilai downtime metode Nth lebih singkat dibandingkan dengan metode PCC dimana nilai maksimum downtime metode Nth hanya sebesar $4 \mathrm{~s}$ dibanding dengan nilai maksimum downtime metode PCC sebesar $5 \mathrm{~s}$.

\section{UCAPAN TERIMA KASIH}

Terima kasih kepada Unit Penelitian dan Pengabdian kepada Masyarakat (UPPM) Politeknik Negeri Ujung Pandang.

\section{REFERENSI}

[1] R. Nur, Z. Saharuna, and R. Wahyuni, "Gateway Redundancy Using Common Address Redundancy Protocol ( CARP )," vol. 2, no. 3, 2018

[2] I. M. W. Wirawan, "Implementasi Load Balance Pada Jaringan Multihoming Menggunakan Router Dengan Metode Round Robin," J. Ilmu Komput. UNUD, vol. 4, no. 1, pp. 1522, 2011.

[3] R. Ramandito, "Analisis Performace Jaringan Komputer Dengan Mekanisme Load Balancing-Failover," Jurnal Teknik Elektro dan Teknologi Informasi UGM, vol. 3, no. 4. pp. 177$181,2010$.

[4] A. Husni et al., "Teknik Load Balancing Menggunakan Metode Equal Cost Multi Path ( Ecmp ) Untuk Mengukur Beban Traffic Di Diskominfo Tenggarong," vol. 3, no. 1, pp. 103-109, 2018.

[5] T. Sukendar, "Keseimbangan Bandwidth Dengan Menggunakan Dua ISP Melalui Metode Nth Load Balancing Berbasiskan Mikrotik," J. Tek. Komput. Amik Bsi, vol. III, no. 1, pp. 86-92, 2017.

[6] I. Warman and A. Andrian, "Analisis Kinerja Load Balancing Dua Line Kineksi DenganN Metode Nth ( Studi Kasus: Laboratorium Teknik Informatika Institut Teknologi Padang )," Teknoif, vol. 5, no. 1, pp. 56-62, 2017.

[7] A. W. Syaputra and S. Assegaff, "Analisis Dan Implementasi Load Balancing Dengan Metode Nth Pada Jaringan Dinas Pendidikan Provinsi Jambi," Anal. Dan Implementasi Load Balanc. Dengan Metod. Nth Pada Jar. Dinas Pendidik. Provinsi Jambi, vol. 2, no. 4, pp. 831-844, 2017.

[8] R. Rasna and A. Ashari, "Application of Load Balancing with the Nth Method on Multiple Gateway Internet Networks," IJCCS (Indonesian J. Comput. Cybern. Syst., vol. 13, no. 2, p 159, 2019.

[9] P. Soepomo, "IMPLEMENTASI PROXY SERVER DAN LOAD BALANCING MENGGUNAKAN METODE PER CONNECTION CLASSIFIER (PCC) BERBASIS MIKROTIK (Studi kasus : Shmily.net)," J. Sarj. Tek. Inform. vol. 2, no. 2, pp. 409-420, 2014.
[10] Suzanzefi, F. Utami, and Lindawati, "Optimalisasi Load Balancing Dua Isp Untuk Manajemen Bandwidth Berbasis Mikrotik," Pros. Semin. Nas. Multi Disiplin Ilmu Call Pap. SNATI F, no. 4, pp. 451-457, 2017.

[11] M. F. Adani, Jusak, and H. Pratikno, "Analisis Perbandingan Metode Load Balance Pcc Dengan Nth Menggunakan Mikrotik," J. Control Netw. Syst., vol. 5, no. 1, pp. 119-125, 2016.

[12] M. Y. Choirullah, M. Anif, and A. Rochadi, "Analisis Kualitas Layanan Virtual Router Redundancy Protocol Menggunakan Mikrotik pada Jaringan VLAN," J. Nas. Tek. Elektro dan Teknol. Inf., vol. 5, no. 4, pp. 278-285, 2016.

[13] I. Iskandar and A. Hidayat, "Analisa Quality of Service (QoS) Jaringan Internet Kampus (Studi Kasus: UIN Suska Riau),” J. CoreIT, vol. 1, no. 2, pp. 67-76, 2015.

[14] Y. A. Pranata, I. Fibriani, and S. B. Utomo, "Analisis Optimasi Kinerja Quality of Service Pada Layanan Komunikasi Data Menggunakan Ns-2 Di Pt. Pln (Persero) Jember," Sinergi, vol. 20, no. 2, p. 149, 2016.

[15] R. Nur, Z. Saharuna, D. Jurusan, T. Elektro, P. Negeri, and U. Pandang, "ANALISIS QUALITY OF SERVICE ( QOS ) PADA INFRASTRUKTUR DATA CENTRE Kategori Delay Sangat bagus Bagus Sedang Buruk Indeks," vol. 2018, pp. 197-202, 2018. 